Original Article

\title{
Profiling of remote skeletal muscle gene changes resulting from stimulation of atopic dermatitis disease in $\mathrm{NC} / \mathrm{Nga}$ mouse model
}

\author{
Donghee Lee', Yelim Seo', Young-Won Kim', Seongtae Kim', Jeongyoon Choi', Sung-Hee Moon', Hyemi Bae', \\ Hui-sok Kim², Hangyeol Kim², Jae-Hyun Kim², Tae-Young Kim², Eunho Kim², Suemin Yim², Inja Lim', \\ Hyoweon Bang ${ }^{1}$, Jung-Ha Kim ${ }^{3, *}$, and Jae-Hong Ko ${ }^{1, *}$
}

Departments of ${ }^{1}$ Physiology and ${ }^{2}$ Medicine, Chung-Ang University College of Medicine, Seoul 06974, ${ }^{3}$ Department of Family Medicine, Chung-Ang University Hospital, Chung-Ang University College of Medicine, Seoul 06973, Korea

\section{ARTICLE INFO}

Received June 29, 2019

Revised July 7, 2019

Accepted July 9, 2019

*Correspondence

Jae-Hong Ko

E-mail: akdongyi01@cau.ac.kr

Jung-Ha Kim

E-mail: girlpower219@cau.ac.kr

Key Words

Cytokines

Dermatitis, atopic

Microarray analysis

Mitochondria

\begin{abstract}
Although atopic dermatitis (AD) is known to be a representative skin disorder, it also affects the systemic immune response. In a recent study, myoblasts were shown to be involved in the immune regulation, but the roles of muscle cells in AD are poorly understood. We aimed to identify the relationship between mitochondria and atopy by genome-wide analysis of skeletal muscles in mice. We induced AD-like symptoms using house dust mite (HDM) extract in NC/Nga mice. The transcriptional profiles of the untreated group and HDM-induced AD-like group were analyzed and compared using microarray, differentially expressed gene and functional pathway analyses, and protein interaction network construction. Our microarray analysis demonstrated that immune response-, calcium handling-, and mitochondrial metabolism-related genes were differentially expressed. In the Kyoto Encyclopedia of Genes and Genomes (KEGG) and Gene Ontology pathway analyses, immune response pathways involved in cytokine interaction, nuclear factor-kappa B, and T-cell receptor signaling, calcium handling pathways, and mitochondria metabolism pathways involved in the citrate cycle were significantly upregulated. In protein interaction network analysis, chemokine family-, muscle contraction process-, and immune response-related genes were identified as hub genes with many interactions. In addition, mitochondrial pathways involved in calcium signaling, cardiac muscle contraction, tricarboxylic acid cycle, oxidation-reduction process, and calcium-mediated signaling were significantly stimulated in KEGG and Gene Ontology analyses. Our results provide a comprehensive understanding of the genome-wide transcriptional changes of HDM-induced AD-like symptoms and the indicated genes that could be used as AD clinical biomarkers.
\end{abstract}

\section{INTRODUCTION}

Atopic dermatitis (AD) is a common problem that affects many people from infancy and is caused by a variety of allergens, including environmental factors and foods [1,2]. AD is accompanied by intractable itching-a common symptom of systemic diseases-including peripheral and central nervous system itch and pruritoceptive components, such as skin dryness [3]. Under the conditions of central sensitization, painful irritation is usually perceived as itching [4]. Severe itching may also cause a secondary infection. As such, itching is a major part of the pain disorder.

Recent studies have suggested that myoblasts can act as antigen-presenting cells in the immune response in muscles, and have been proposed as potential neoantigens in the inflammatory (i) (s) This is an Open Access article distributed under the terms of the Creative Commons Attribution Non-Commercial License, which permits unrestricted non-commercial use, distribution, and reproduction in any medium, provided the original work is properly cited. Copyright $\odot$ Korean J Physiol Pharmacol, pISSN 1226-4512, elSSN 2093-3827
Author contributions: D.L. analyzed the data and wrote the manuscript. Y.S., Y.W.K., I.L., H.B., and S.K. analyzed the microarray data. J.C., S.H.M., and H.B. performed animal experiments. H.S.K., H.K., J.H.K., T.Y.K., E.K., and S.Y. performed molecular experiments. J.H.K. ${ }^{3}$ and J.H.K. designed the study. 
response [5-7]. Myoblasts are considered active participants in the immune response and secrete or regulate the expression of various cytokines, chemokines, and cell adhesion molecules such as interleukin 6 (Il6), Il2, Cd4, and Cd8 [7-9]. For example, the airway smooth muscle can modulate immune responses through cell surface receptor-mediated recognition of various molecules such as Il6, Il8, and Il11 [10,11].

Allergen-induced mitochondrial dysfunction and increased production of reactive oxygen species (ROS) have been demonstrated in a variety of allergic rhinitis and AD cases [12]. ROS are byproducts of mitochondrial respiration, which play roles in antibacterial immune signaling and phagocyte bactericidal activity [13]. Furthermore, increased mitochondrial numbers and densities were observed in patients with severe asthma [14,15]. This is consistent with a previous study demonstrating that allergeninduced early asthmatic responses are associated with glycolysis, $\mathrm{Ca}^{2+}$ binding, and mitochondrial activity [16], and a genome-wide study of allergic rhinitis that suggested the involvement of a mitochondrial pathway [17]. In addition, the development of atopic allergic diseases in children is strongly associated with genetics [18], particularly maternal atopic history [19-21]. Furthermore, sequence changes in the mitochondria, which are maternally inherited, are related to the pathogenesis of asthma and $\mathrm{AD}[12,22]$. Thus, recent approaches to treating allergic disease target the mitochondria [23], and we anticipate that this may also be an effective strategy for treating $\mathrm{AD}$.

$\mathrm{AD}$ is known to be a representative skin disorder, but it also affects the systemic immune response [24,25]. In a recent study, myoblasts were shown to be involved in the immune response as antigen presenting cells; however, other roles of muscle cells in $\mathrm{AD}$ are poorly understood. In this study, we used a murine model of atopic dermatitis (NC/Nga) that was induced by house dust mite (HDM) extract to measure changes in skeletal muscle. Specifically, we performed a genome-wide transcriptional analysis, microarray analysis, and quantitative reverse transcriptionpolymerase chain reaction (qRT-PCR) to measure changes in gene expression and determine differences in protein interaction networks. In addition, we measured the mitochondrial DNA copy number to investigate the mitochondrial changes caused by $\mathrm{AD}$ induction.

\section{METHODS}

\section{Animals and groups}

Nine-week-old female NC/Nga mice weighing 23-27 g were purchased from Central Lab Animal Inc. (Seoul, Korea) and allowed to acclimate for 2 weeks before the experiments were initiated. The mice were divided into the $\mathrm{AD}$-induced group and the no treatment group ( $\mathrm{n}=2$ /group). Mice were housed in a standard, controlled environment: $22 \pm 3^{\circ} \mathrm{C}, 50 \pm 10 \%$ humid- ity, 12-h light-dark cycle, and ventilation 10-15 times/h with a wind velocity of $10-20 \mathrm{~cm} / \mathrm{s}$. All animal studies were conducted in accordance with the guidelines for animal testing and were approved by the institutional Ethics Committee of the Chung-Ang University, Korea (approval no. 201800012).

\section{Induction of AD}

$\mathrm{AD}$ was induced using Biostir AD cream containing Dermatophagoides farinae extract (Central Lab Animal Inc.) following the manufacturer's instructions. Briefly, the hair behind the ears and backs of the mice was removed using scissors and a razor, and $150 \mu \mathrm{l}$ of $4 \%$ sodium dodecyl sulfate solution was evenly dispersed on the shaved skin to create a barrier rupture. The solution was dried using a hair dryer (cold air setting) for 2-3 h, and $100 \mathrm{mg}$ of the cream was uniformly applied on the shaved skin. Biostir AD was applied twice per week for 8 weeks. Before the second treatment, the hair was shaved if it had grown back. Mice were sacrificed under anesthesia and blood samples were collected from the abdominal aorta. Gluteal muscles were rapidly removed and washed at least three times in phosphate-buffered saline.

\section{Microarray}

The Affymetrix Whole-transcript Expression array was used according to the manufacturer's protocol (GeneChip Whole Transcript [WT] PLUS reagent kit; Affymetrix, Santa Clara, CA, USA). Complementary DNA was reverse-transcribed from the mouse gluteal muscle tissue using the GeneChip WT amplification kit (Affymetrix) following the manufacturer's instructions. The sense complementary DNA was then fragmented and biotinlabeled with terminal deoxynucleotidyl transferase using the GeneChip WT Terminal labeling kit (Affymetrix). Approximately $5.5 \mu \mathrm{g}$ of labeled DNA target was hybridized to the Affymetrix GeneChip mouse 2.0 ST Array (Affymetrix) at $45^{\circ} \mathrm{C}$ for $16 \mathrm{~h}$. Hybridized arrays were washed and stained on a GeneChip Fluidics Station 450 and scanned on a GCS3000 Scanner (Affymetrix). Fluorescent signal values were measured using the Affymetrix GeneChip Command Console software (Affymetrix).

\section{Determination of a differentially expressed genes (DEGs) interaction network}

A protein-protein interaction network analysis was performed to determine the protein-protein interactions between DEGs that had been identified by the microarray analysis. DEGs with foldchange values $<1.5$ and p-values $<0.05$ were analyzed by Search Tool for the Retrieval of Interacting Genes (STRING) version 10.5 (http://www.string-db.org/) using the highest confidence minimum interaction score of 0.900 . 


\section{Measurement of mitochondrial DNA copy number}

Total DNA was extracted from the mouse gluteal muscle using the QIAamp DNA mini kit (Qiagen, Hilden, Germany) according to the manufacturer's instructions. NADH dehydrogenase 4 (Nd4), D-loop, cytochrome $c$ oxidase I (Cox1), and glyceraldehyde 3-phosphate dehydrogenase (Gapdh) were amplified by realtime PCR using a LightCycler 2.0 (Roche, Mannheim, Germany). Each $10-\mu \mathrm{l}$ reaction contained $2 \mathrm{mM} \mathrm{MgCl} 2,0.5 \mu \mathrm{M}$ of each primer, 1x Light-Cycler DNA Master SYBR Green I (Roche), and $15 \mathrm{ng}$ of DNA template. All primer sequences are listed in Table 1. The reaction conditions were as follows: denaturation $\left(95^{\circ} \mathrm{C}\right.$ for $10 \mathrm{~min})$, amplification for 35 cycles $\left(95^{\circ} \mathrm{C}\right.$ for $10 \mathrm{sec} ; 62^{\circ} \mathrm{C}$ for 10 sec; $72^{\circ} \mathrm{C}$ for $\left.10 \mathrm{sec}\right)$, a melting curve program $\left(65^{\circ} \mathrm{C}\right.$ to $95^{\circ} \mathrm{C}$ with a heating rate of $\left.0.1^{\circ} \mathrm{C} / \mathrm{sec}\right)$, and a cooling step $\left(40^{\circ} \mathrm{C}\right)$. The results are expressed as the ratio of mtDNA to gDNA and compared as previously described [26].

\section{Raw data preparation and statistical analysis}

The data were summarized and normalized with the robust multi-average method implemented in Affymetrix Power Tools. Gene levels were used to perform the DEG analysis. Statistically significant fold changes were determined using the local pooled error test. The false discovery rate (FDR) was controlled using the Benjamini-Hochberg algorithm. For each DEG set, hierarchical cluster analysis was performed using complete linkage and $\mathrm{Eu}-$ clidean distance as a measure of similarity. Gene-Enrichment and Functional Annotation analysis for the list of significant genes was performed using Gene Ontology (GO; http://geneontology. org) and Kyoto Encyclopedia of Genes and Genomes (KEGG; http://kegg.jp). All data analysis and visualization of DEGs was conducted using R 3.0.2 (www.r-project.org). Statistical significance between the control group and experimental group was determined using Student's t-test, Bonferroni correction, and the FDR. In all cases, $\mathrm{p}$-values $<0.05$ were considered significant.

Table 1. The primer sequences and annealing temperatures for PCR

\begin{tabular}{|c|c|c|c|}
\hline $\begin{array}{l}\text { Gene } \\
\text { symbol }\end{array}$ & Primer sequence & $\begin{array}{c}\text { Annealing } \\
\text { temperature } \\
\left({ }^{\circ} \mathrm{C}\right)\end{array}$ & $\begin{array}{c}\text { Product } \\
\text { size } \\
\text { (bp) }\end{array}$ \\
\hline $\mathrm{Nd} 4$ & $\begin{array}{l}\text { ATAGCCACATGATGACTGATAGC } \\
\text { TGCCGCGTTGGGTGGTAA }\end{array}$ & 58 & 190 \\
\hline D-loop & $\begin{array}{l}\text { AGCTACTCСССАССАCСAG } \\
\text { TGACGGCTATGTTGATGAAAGT }\end{array}$ & 60 & 128 \\
\hline Cox1 & $\begin{array}{l}\text { GAGCAATCCAGGTCGGTTTC } \\
\text { CTTACGCAATTTCCTGGCTCTG }\end{array}$ & 55 & 184 \\
\hline Gapdh & $\begin{array}{l}\text { TGCTTCACCACCTTCTTGAT } \\
\text { TGGAAAGCTGTGGCGTGAT }\end{array}$ & 58 & 217 \\
\hline
\end{tabular}

www.kjpp.net

\section{RESULTS}

Measurement of gene expression changes in skeletal muscle from the murine HDM-induced AD model by microarray analysis

Microarray analysis using mouse gluteal muscle total mRNA was performed for the control and the AD model groups. A total of 35,240 transcripts were detected, and 2,394 DEGs were detected between the two conditions-1591 genes were up-regulated and 803 were down-regulated (FC > 1.5) (Fig. 1A). In comparing the two groups, 421 genes were significantly dysregulated with FC values $>1.5$ and p-values $<0.05$, and 416 genes were significantly dysregulated with FC values $>2$ and p-values $<0.05$ (Fig. 1B). The significantly dysregulated 421 DEGs are listed in Supplementary Table 1. The top 30 differentially expressed up-regulated and down-regulated genes between the two conditions and their pvalues are listed in Tables 2 and 3, respectively.

\section{KEGG analysis of the significant pathways altered in} $A D$

The significantly regulated pathways were determined according to the functions and interactions of DEGs based on the KEGG database. The 2,394 DEGs significantly stimulated by the

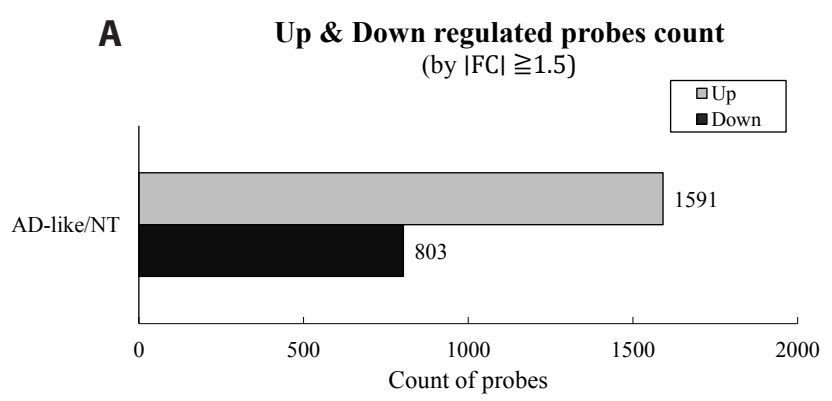

B

Significant probes count (by $|\mathrm{FC}| \geqq 1.5$ or $2 \& P$-value $<0.05$ )

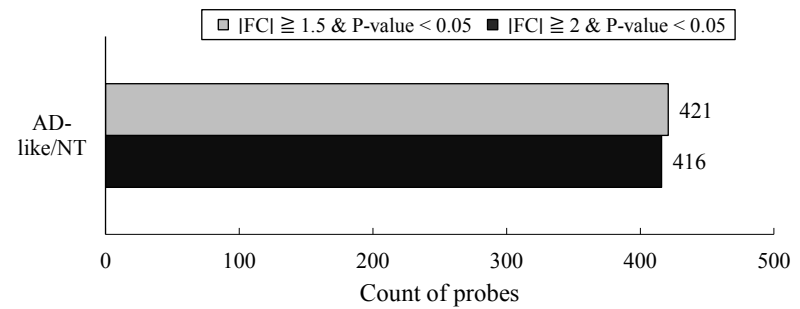

Fig. 1. Regulated probes through house dust mite-induced atopic dermatitis (AD)-like in microarray analysis by fold change (FC) and p-value. (A) Up- and downregulated probes count compared between the AD-like (Itch) group and non-treated (NT) group ( $|F C|<2)$. (B) Significantly regulated probes count compared between the Itch group and NT group ( $|F C|<1.5$ and 2 with $p$-value $<0.05$ ). 
Table 2. Top 30 up-regulated genes identified by microarray analysis

\begin{tabular}{|c|c|c|c|}
\hline Gene name & Gene symbol & Fold-change & p-value \\
\hline Immunoglobulin heavy chain (V3609N non-productive) & $\operatorname{lgh}-\mathrm{V} 3609 \mathrm{~N}$ & 37.1754 & 0 \\
\hline Glycosylation dependent cell adhesion molecule 1 & Glycam1 & 35.4278 & 0 \\
\hline Myosin, heavy polypeptide 7 , cardiac muscle, beta & Myh7 & 25.3377 & 0 \\
\hline Immunoglobulin kappa variable 5-48 & $\lg k v 5-48$ & 19.2719 & 0 \\
\hline Immunoglobulin kappa variable 6-17 & $\lg k v 6-17$ & 18.7449 & 0 \\
\hline Immunoglobulin kappa chain variable 4-70 & $\operatorname{lgkv4-70}$ & 18.6879 & 0 \\
\hline Immunoglobulin kappa variable 4-57-1 & Igkv4-57-1 & 16.2358 & 0 \\
\hline Immunoglobulin kappa variable 10-96 & $\operatorname{lgkv10-96}$ & 16.2052 & 0 \\
\hline Immunoglobulin kappa variable 6-23 & $\lg k v 6-23$ & 15.8888 & 0 \\
\hline Cysteine and glycine-rich protein 3 & Csrp3 & 15.6094 & 0 \\
\hline Protein tyrosine phosphatase, receptor type, C & Ptprc & 14.9040 & 0 \\
\hline Immunoglobulin kappa joining 1 & $\lg k j 1$ & 14.6315 & 0 \\
\hline Immunoglobulin heavy chain (X24 family) & $\operatorname{lgh}-V \times 24$ & 14.2970 & 0 \\
\hline Immunoglobulin kappa chain variable 4-72 & $\operatorname{lgkv4-72}$ & 12.9740 & 0 \\
\hline CD3 antigen, gamma polypeptide & $C d 3 g$ & 12.8406 & 0 \\
\hline Apolipoprotein L 7c & Apol7c & 12.1598 & 0 \\
\hline Immunoglobulin heavy variable 3-2 & lghv3-2 & 11.8548 & 0 \\
\hline Immunoglobulin heavy variable 1-34 & Ighv1-34 & 11.7469 & 0 \\
\hline Troponin C, cardiac/slow skeletal & Tnnc1 & 11.2839 & 0 \\
\hline T cell receptor alpha constant & Trac & 11.1193 & 0 \\
\hline Immunoglobulin kappa variable 3-7 & $\lg k v 3-7$ & 10.9758 & 0 \\
\hline CD53 antigen & Cd53 & 10.4683 & 0 \\
\hline Immunoglobulin kappa variable 3-12 & $\operatorname{lgkv3-12}$ & 10.4207 & 0 \\
\hline Immunoglobulin kappa variable 1-135 & $\lg k v 1-135$ & 10.0585 & 0 \\
\hline Chemokine (C-X-C motif) ligand 13 & Cxcl13 & 9.5213 & 0 \\
\hline Trans-2,3-enoyl-coa reductase-like & Tecrl & 9.3244 & 0 \\
\hline Complement receptor 2 & Cr2 & 9.2697 & 0 \\
\hline Membrane-spanning 4-domains, subfamily A, member 1 & Ms4a1 & 8.6954 & 0 \\
\hline Atpase, Ca++ transporting, cardiac muscle, slow twitch 2 & Atp2a2 & 8.3273 & 0 \\
\hline Immunoglobulin kappa variable 6-14 & $\operatorname{lgkv6-14}$ & 8.3243 & $6.26188 \mathrm{E}-11$ \\
\hline
\end{tabular}

AD-like condition were correlated with the Database for Annotation, Visualization, and Integrated Discovery and the KEGG pathway mapper to determine the pathways stimulated by $\mathrm{AD}$ like. Based on KEGG pathway analysis, 136 signaling pathways were identified, including cytokine-cytokine receptor interactions, metabolic, nuclear factor (NF)-kappa B signaling, chemokine signaling, B cell receptor signaling, cell adhesion molecules, and $\mathrm{T}$ cell receptor signaling $(\mathrm{p}<0.001)$. The top 20 significantly regulated pathways are shown in Fig. 2 , including cytokine-cytokine receptor interactions, metabolic pathways, cancer-associated pathways, NF-kappa B signaling, chemokine signaling pathways, leukocyte transendothelial migration, hematopoietic cell lineage, B cell receptor signaling pathway, tuberculosis, cell adhesion molecules, $\mathrm{T}$ cell receptor signaling, phagosome, regulation of actin cytoskeleton, Th17 cell differentiation, phosphoinositide3-kinase (PI3K)-Akt signaling pathway, toxoplasmosis, human T-cell lymphotropic virus type I infection, nucleotide-binding oligomerization domain (NOD)-like receptor signaling pathway, Janus kinase-signal transducers and activators of transcription (Jak-STAT) signaling pathway, and measles.

The top 30 pathways except for disease-related pathways, and the top 10 genes for each pathway with their respective p-values are shown in Supplementary Table 2. The significantly regulated pathways included cytokine-cytokine receptor interaction, metabolic, NF-kappa B signaling, chemokine signaling, leukocyte transendothelial migration, hematopoietic cell lineage, B cell receptor signaling, cell adhesion molecules, $\mathrm{T}$ cell receptor signaling, phagosome, regulation of actin cytoskeleton, Th17 cell differentiation, PI3K-Akt signaling pathway, NOD-like receptor signaling pathway, Jak-STAT signaling pathway, primary immunodeficiency, osteoclast differentiation, antigen processing and presentation, Th1 and Th2 cell differentiation, intestinal immune network for immunoglobulin A production, endocytosis, natural killer cell-mediated cytotoxicity, mitogen-activated protein kinase signaling pathway, Toll-like receptor signaling pathway, cardiac muscle contraction, adrenergic signaling in cardiomyocytes, hypertrophic cardiomyopathy, cyclic adenosine monophosphate signaling pathway, tumor necrosis factor signaling pathway, and calcium signaling $(\mathrm{p}<0.001)$.

Specific to cytokine-cytokine receptor interaction pathways, the analysis showed that $C x c 113$, interleukin 2 receptor gamma chain (Il2rg), Cd4, Il7r, chemokine ligand 5 (Ccl5), lymphotoxin B (Ltb), Ccl22, Lep, Cd27, and chemokine receptor 7 (Ccr7) were significantly altered in the AD model $(\mathrm{p}=2.7 \mathrm{E}-36)$. Regarding 
Table 3. Top 30 down-regulated genes identified by microarray analysis

\begin{tabular}{|c|c|c|c|}
\hline Gene name & Gene symbol & Fold-change & p-value \\
\hline Casein alpha s1 & Csn1s1 & -7.6527 & 2.26399E-11 \\
\hline Casein beta & Csn2 & -7.3311 & 7.34889E-11 \\
\hline Mucin 15 & Muc15 & -3.7743 & 0.00035 \\
\hline Casein kappa & Csn3 & -3.7083 & 0.00035 \\
\hline Fc fragment of igg binding protein & Fcgbp & -3.6153 & 0.00010 \\
\hline Casein alpha s2-like A & $\operatorname{Csn} 1 s 2 a$ & -3.2033 & 0.00587 \\
\hline Lactotransferrin & $L t f$ & -3.0503 & 0.00373 \\
\hline Myosin binding protein $\mathrm{H}$ & Mybph & -3.0011 & 0.00001 \\
\hline Phosphoenolpyruvate carboxykinase 1, cytosolic & Pck1 & -2.8493 & 0.00015 \\
\hline Actin, alpha, cardiac muscle 1 & Actc1 & -2.7027 & 0.00001 \\
\hline Cadherin 4 & Cdh4 & -2.6432 & 0.00077 \\
\hline Leptin & Lep & -2.6211 & 0.00106 \\
\hline Angiopoietin-like 4 & Angptl4 & -2.6158 & 0.00290 \\
\hline Amine oxidase, copper containing 3 & Aoc3 & -2.6102 & 0.00098 \\
\hline Phospholipase A2, group VII (platelet-activating factor acetylhydrolase, plasma) & Pla2g7 & -2.6038 & 0.00103 \\
\hline Keratin 18 & Krt18 & -2.6004 & 0.02743 \\
\hline Thyroid hormone responsive & Thrsp & -2.5871 & 0.00116 \\
\hline Glycogen synthase 2 & Gys2 & -2.5275 & 0.01502 \\
\hline Lipocalin 2 & Lcn2 & -2.5197 & 0.00591 \\
\hline Microtubule associated monooxygenase, calponin and LIM domain containing 2 & Mical2 & -2.5104 & 0.00136 \\
\hline Prolactin receptor & Prlr & -2.4817 & 0.07528 \\
\hline Sine oculis-related homeobox 2 & Six2 & -2.4166 & 0.03186 \\
\hline Chloride intracellular channel 6 & Clic6 & -2.3845 & 0.14195 \\
\hline Orosomucoid 1 & Orm1 & -2.3769 & 0.01169 \\
\hline Lectin, galactose binding, soluble 12 & Lgals12 & -2.3761 & 0.00568 \\
\hline Protein kinase, AMP-activated, gamma 3 non-catatlytic subunit & Prkag3 & -2.3624 & 0.00590 \\
\hline Serine (or cysteine) peptidase inhibitor, clade B, member 9e & Serpinb9e & -2.2775 & 0.25753 \\
\hline Synuclein, gamma & Sncg & -2.2739 & 0.01138 \\
\hline Transmembrane protease, serine 2 & Tmprss2 & -2.2438 & 0.13079 \\
\hline Calcium channel, voltage-dependent, gamma subunit 1 & Cacng1 & -2.2426 & 0.01124 \\
\hline
\end{tabular}

metabolic pathways, the following genes were significantly altered: UDP-glucose ceramide glucosyltransferase (Ugcg), phosphoenolpyruvate carboxykinase 1 cytosolic (Pck1), ADP-ribosyltransferase $2 \mathrm{~b}$ (Art2b), mannosidase 1 alpha (Man1a), amine Aoc3, phospholipase A2 group 7 (Pla2g7), heparinase (Hpse), phospholipase C gamma 2 (Plcg2), inositol polyphosphate4-phosphatase type 2 (Inpp4b), and Fasn ( $\mathrm{p}=7.5 \mathrm{E}-28)$.

\section{GO function analysis of the significant pathways altered in $A D$}

GO function analysis was used to determine the main gene functions affected by HDM treatment. An interaction network of significant GO terms was assembled into a GO map to determine the prominent functional categories. The GO functions of the DEGs were determined according to categories that included biological process, molecular functions, and cellular components. In the biological process category, single-organism, cellular, biological regulation, single-organism cellular, single-organism developmental, developmental, single-multicellular organism, anatomical structure development, and multicellular organismal processes were identified (Fig. 3A). In the cellular component category, extracellular, organelle, membrane-bound, and cytoplasmic function were identified (Fig. 3B). In the molecular component category, protein binding, protein dimerization activity, catalytic activity, anion and cation binding, and metal ion binding functions were identified (Fig. 3C).

The 30 significantly regulated pathways, their p-values, and FDRs are listed in Table 4. Single-organism process, cellular process, biological regulation, single-organism cellular process, cell part, cell, single-organism developmental process, extracellular region, developmental process, organelle, extracellular region part, regulation of biological process, single-multicellular organism process, anatomical structure development, protein binding, multicellular organismal process, binding, multicellular organismal development, system development, membrane-bounded organelle, response to stimulus, small molecule metabolic process, lipid metabolic process, regulation of multicellular organismal process, regulation of cellular process, organ development, negative regulation of biological process, intracellular part, muscle structure development, and cytoplasmic part were significantly altered in response to HDM treatment $(\mathrm{p}<0.001)$. 


\section{Significantly stimulated pathway in KEGG}

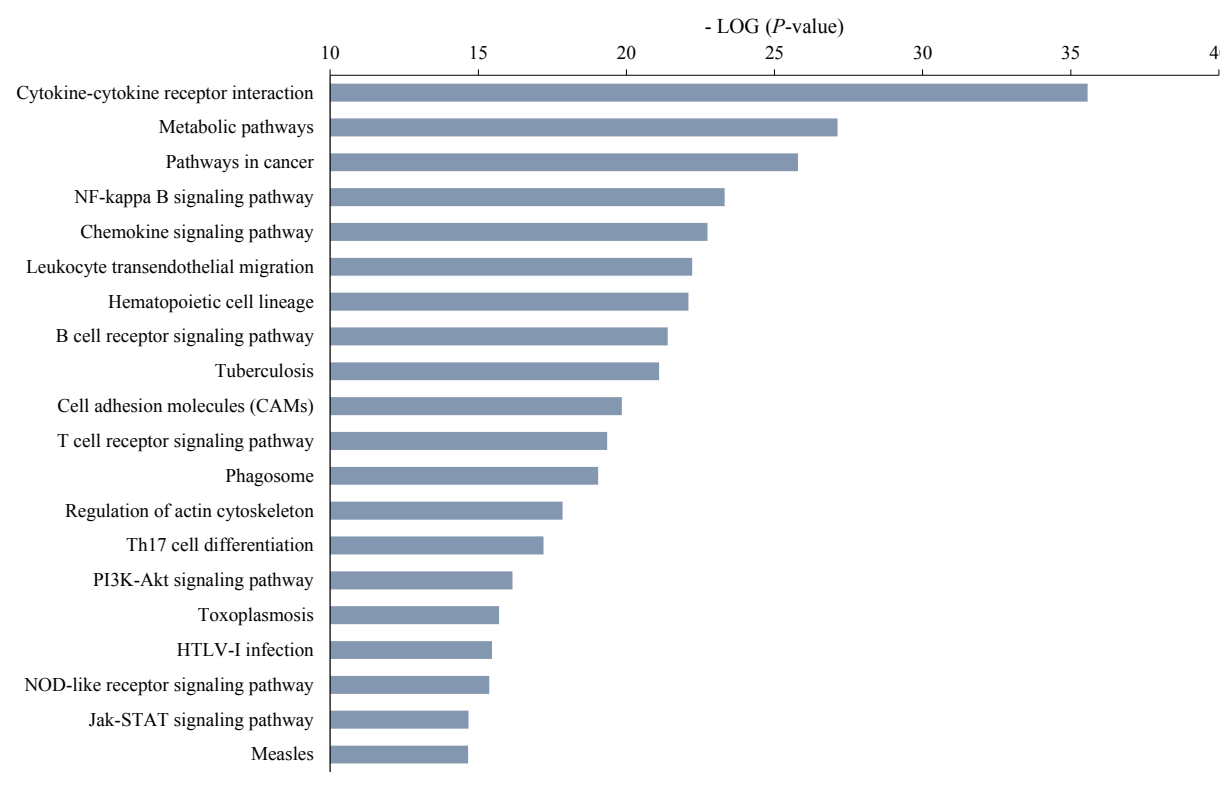

Fig. 2. The top 20 most significantly stimulated pathways in Kyoto Encyclopedia of Genes and Genomes (KEGG) pathway analysis by house dust mite-induced atopy dermatitislike. The $p$-value is expressed in log format. NF, nuclear factor; PI3K, phosphoinositide-3-kinase; HTLV-I, human T-cell lymphotropic virus type I; NOD, nucleotide-binding oligomerization domain; Jak-STAT, Janus kinase-signal transducers and activators of transcription.

\section{Correlation of DEGs in interaction network analysis}

Based on the GO and KEGG pathway analysis, the protein interaction analysis was performed to determine the hub genes involved in HDM-induced AD-like in the NC/Nga mouse. We used the STRING database of interactions to reveal a putative protein association network based on the microarray data [27]. Network analysis was performed on 187 significant DEGs, 98 of which were found in STRING $(\mathrm{p}<0.01,|\mathrm{FC}|<1.5)$. The interaction relationship network of genes is shown in Supplementary Fig. 1. The hub genes, $C x c 15, C x c r 13, C c 15, C c l 21 c, C c r 5, C c r 7$, actinin alpha 2 (Actn2), actin alpha cardiac muscle 1 (Actc1), troponin I skeletal slow 1 (Tnni1), tropomyosin 3 gamma (Tpm3), myosin light polypeptide 3 (Myl3), myosin heavy polypeptide 7 cardiac muscle beta (Myh7), myosin binding protein C slow-type (Mybpc1), troponin T1 skeletal slow (Tnnt1), troponin C cardiacl slow skeletal (Tnnc1), $C d 3 d, C d 3 e, C d 3 g, C d 4, C d 74$, histocompatibility 2 class II antigen A alpha (H2-aa), H2-ab1, H2-dma, cathepsin S (Ctss), and protein tyrosine phosphatase non-receptor type 6 (Ptpn6), had more than 10 interactions and were located in the center of the network. The chemokines, $\mathrm{Cxcl5}, \mathrm{Cxcr13}, \mathrm{Ccl} 5$, Ccl21c, Ccr5, and Ccr7, were included [28], as well as genes involved in muscle contraction, such as Actn2, Actc1, Tnnil, Tpm3, Myl3, Myh7, Mybpc1, Tnnt1, Tnnc1, and Tnni1 [29]. The immune and inflammatory response-associated genes, $C d 3 d, C d 3 e, C d 3 g$, Cd4, H2-aa, H2-ab1, Cd74, H2-dma, Ctss, and Ptpn6, were also included in the network [30].

\section{Mitochondrial function-related gene effects in response to $A D$}

Based on the KEGG and GO analyses shown in Supplemen- tary Tables 2 and Table 4, respectively, the pathways involved in mitochondrial metabolism, such as calcium signaling pathway (KEGG:04020), cardiac muscle contraction (KEGG:04260), tricarboxylic acid cycle (KEGG:0020), oxidation-reduction process (GO:0055114), calcium-mediated signaling (GO:0019722), and mitochondrion (GO:0005739) were significantly stimulated by AD-like. The DEGs in these pathways involved in mitochondrial function are listed in Table 5. Phospholipase C, delta 4 (PIcd4), Plcg2, Tnnc1, PTK2 protein tyrosine kinase 2 beta (Ptk2b), and protein kinase $\mathrm{C}$ beta $(P r k c b)$, which are associated with calcium signaling, were significantly stimulated (FDR:0.001338772) by KEGG analysis. For cardiac muscle contraction, Atp2a2, Tnnc1, Tpm2, Tpm3, Tpm4, Actc1, Myh2, Myh3, Myh4, and Myh7 were also significantly stimulated (FDR:2.86478E-09). In the tricarboxylic acid cycle, $P c k 1$, pyruvate dehydrogenase beta $(P d h b)$, pyruvate carboxylase $(P c x)$, ATP citrate lyase $(A c l y)$, isocitrate dehydrogenase $2(L d h 2)$, and dihydrolipoamide dehydrogenase (Dlb) were significantly stimulated (FDR:0.001761341). Acetylcoenzyme A acyltransferase 2 (Acaa2), solute carrier family 25 member 25 (Slc25a25), cytochrome c oxidase subunit VIIIa (Cox8a), cytochrome b-245, beta polypeptide (Cybb), Fasn, mitochondrial amidoxime reducing component 1 (Marc1), extracellular superoxide dismutase 3 (Sod3), Acly, and uncoupling protein 1 (Ucp1), which are mitochondrial metabolism-related genes, were significantly stimulated based on the microarray analysis. The pathways related to mitochondrial function were selected based on previous studies [31,32].

\section{Mitochondrial DNA copy number}

We performed mitochondrial copy number analysis via qRTPCR using gluteal muscle isolated from the NC/Nga mice. Mi- 

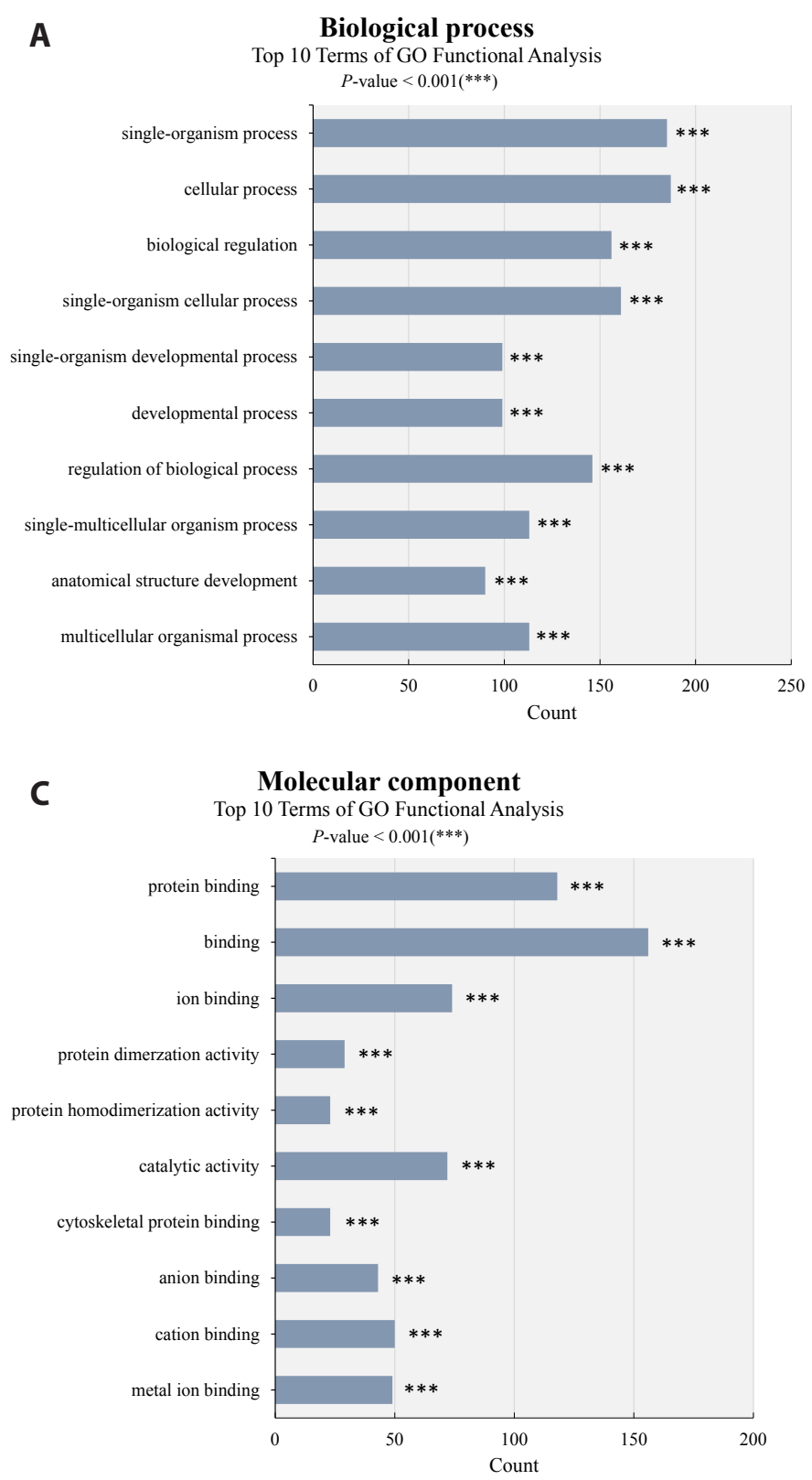

tochondrial copy number measurements were performed three times and averaged. Nd4, D-loop, and Cox1 of mtDNA and $18 S$ of gDNA were intercompared. The results revealed that mtDNA copy numbers were not significantly different between the two groups $(\mathrm{p}<0.01)$ (data not shown).

\section{DISCUSSION}

Immunoglobulin E measurements were performed to confirm that HDM-induced AD-like. We found that the AD-like group had increased immunoglobulin E levels compared to the control group (data not shown), which was consistent with a previous study indicating that HDM induces AD [33]. In addition, we

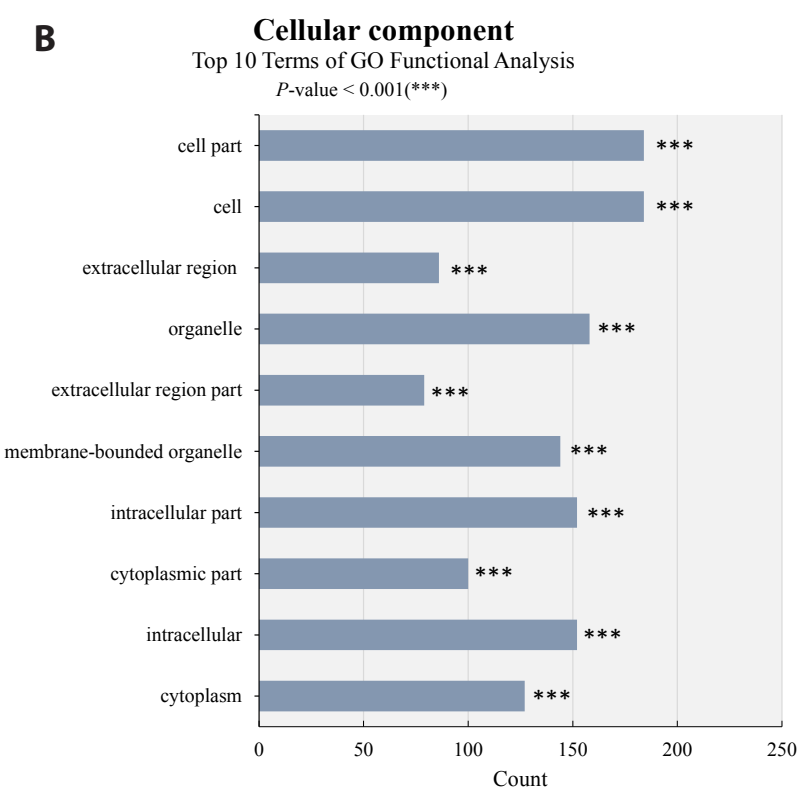

Fig. 3. Analysis of differently expressed genes (DEGs) in Gene Ontology (GO) terms. The Top $10 \mathrm{GO}$ terms and DEGs counts ordered by $\mathrm{p}$-value were categorized in $\mathrm{GO}$ functional analysis sorted by biological process (A), cellular component (B), and molecular component (C). ${ }^{* * *} \mathrm{p}$ $<0.001$.

found that the expression of immune response-associated genes, cytokines, immunoglobulins, and CDs, were up-regulated in the microarray analysis. Thus, HDM successfully induced ADdependent responses in the gluteal muscle.

Microarray analysis was performed to determine mRNA expression changes in response to $\mathrm{HDM}$-induced $\mathrm{AD}$-like, which identified 421 genes and 136 pathways that were significantly altered. The top 30 significantly regulated pathways identified by KEGG and GO analyses primarily identified immune responserelated genes and pathways. Production of cytokines and responses to these molecules are important for regulating immune and inflammatory processes. Chemokines $(\mathrm{Ccl} 5, \mathrm{Ccl} 8, \mathrm{Ccl} 22$, Cxcl12, Cxcl13, Ccr7) and interleukins (Il7r, Il2rg) were significantly up-regulated in response to $\mathrm{AD}$-like, which is consistent 
Table 4. Top 30 significantly enriched terms identified by Gene Ontology (GO) analysis

\begin{tabular}{|c|c|c|c|}
\hline GO top 30 term & GO ID & p-value & FDR \\
\hline Single-organism process & GO:0044699 & $1.77302 \mathrm{E}-27$ & $8.2747 \mathrm{E}-24$ \\
\hline Cellular process & GO:0009987 & $5.07549 \mathrm{E}-23$ & $1.18436 \mathrm{E}-19$ \\
\hline Biological regulation & GO:0065007 & $7.69318 \mathrm{E}-23$ & $1.1968 \mathrm{E}-19$ \\
\hline Single-organism cellular process & GO:0044763 & 4.1294E-21 & 3.85806E-18 \\
\hline Cell part & GO:0044464 & $4.13334 \mathrm{E}-21$ & 3.85806E-18 \\
\hline Cell & GO:0005623 & $6.66731 \mathrm{E}-21$ & 4.5343E-18 \\
\hline Single-organism developmental process & GO:0044767 & 7.40289E-21 & 4.5343E-18 \\
\hline Extracellular region & GO:0005576 & $7.77254 \mathrm{E}-21$ & 4.5343E-18 \\
\hline Developmental process & GO:0032502 & 1.2359E-20 & $6.40885 \mathrm{E}-18$ \\
\hline Organelle & GO:0043226 & $1.73527 \mathrm{E}-20$ & 8.0985E-18 \\
\hline Extracellular region part & GO:0044421 & 2.10197E-20 & 8.91807E-18 \\
\hline Regulation of biological process & GO:0050789 & 4.9866E-20 & $1.93937 \mathrm{E}-17$ \\
\hline Single-multicellular organism process & GO:0044707 & 8.37892E-20 & $3.00803 \mathrm{E}-17$ \\
\hline Anatomical structure development & GO:0048856 & $4.06517 \mathrm{E}-19$ & $1.35515 \mathrm{E}-16$ \\
\hline Protein binding & GO:0005515 & $6.31605 \mathrm{E}-19$ & $1.89788 \mathrm{E}-16$ \\
\hline Multicellular organismal process & GO:0032501 & $6.50655 \mathrm{E}-19$ & $1.89788 \mathrm{E}-16$ \\
\hline Binding & GO:0005488 & $1.85569 \mathrm{E}-18$ & $5.09442 \mathrm{E}-16$ \\
\hline Multicellular organismal development & GO:0007275 & $7.09561 \mathrm{E}-18$ & 1.83973E-15 \\
\hline System development & GO:0048731 & $8.29342 \mathrm{E}-18$ & $2.03713 \mathrm{E}-15$ \\
\hline Membrane-bounded organelle & GO:0043227 & $1.0162 \mathrm{E}-17$ & $2.3713 \mathrm{E}-15$ \\
\hline Response to stimulus & GO:0050896 & $2.7812 \mathrm{E}-17$ & $6.18089 \mathrm{E}-15$ \\
\hline Small molecule metabolic process & GO:0044281 & $4.80876 \mathrm{E}-17$ & $1.02011 \mathrm{E}-14$ \\
\hline Lipid metabolic process & GO:0006629 & $9.70601 \mathrm{E}-17$ & $1.96948 \mathrm{E}-14$ \\
\hline Regulation of multicellular organismal process & GO:0051239 & $1.11721 \mathrm{E}-16$ & $2.1725 \mathrm{E}-14$ \\
\hline Regulation of cellular process & GO:0050794 & $1.92497 \mathrm{E}-16$ & $3.59353 \mathrm{E}-14$ \\
\hline Organ development & GO:0048513 & $5.15211 \mathrm{E}-16$ & 9.24803E-14 \\
\hline Negative regulation of biological process & GO:0048519 & 7.10469E-16 & $1.22806 \mathrm{E}-13$ \\
\hline Intracellular part & GO:0044424 & $7.75892 \mathrm{E}-16$ & 1.29325E-13 \\
\hline Muscle structure development & GO:0061061 & $1.4181 \mathrm{E}-15$ & $2.28216 \mathrm{E}-13$ \\
\hline Cytoplasmic part & GO:0044444 & $1.52592 \mathrm{E}-15$ & $2.37382 \mathrm{E}-13$ \\
\hline
\end{tabular}

FDR, false discovery rate.

with previous studies $[34,35]$. In addition, we showed that $\mathrm{AD}$ related phenotype genes, Il18, Il4ra, Il13ra1, Tlr1, Tlr7, Tlr8, Tlr13, Fcerla, Fcer2a, and Spink51 were upregulated in the microarray analysis [36-38]. Hspala, Stat1, Adam13, and Adam23 were also upregulated and may be useful inflammatory markers [39-42]. We have also studied other genes considered to play integral roles in AD-like. We predicted Igh-v3609n, Glycam1, Igkv5-48, Igkv617, Igkj1, Apol7c, Trac, Cdh4, Thrsp, Gys2, and Lgals12 to play an important role in the AD pathway by microarray and proteinprotein interaction network analysis.

KEGG and GO pathway analyses showed that the pathways represented not only immune response processes but also mitochondrial function. We identified the pathways and genes affected by mitochondria in atopic manifestations and provided a list of mitochondrial-related genes that could be targeted for future treatment of AD-like symptoms. The KEGG pathway analysis showed that the pathways related to calcium signaling, cAMP signaling pathway, cardiac muscle contraction, and citrate cycle were significantly stimulated. The GO pathway analysis showed that the significantly altered genes were related to metabolic process, oxidation-reduction, calcium-mediated signaling, and mitochondrion. Changes in calcium signaling and mitochondrial functionrelated signaling pathways indicated that $\mathrm{AD}$ induction was associated with altered mitochondrial function. Genes involved in the metabolic pathway were Lep, Fasn, Aoc3, Acly, Pck1, Ucp1 and ATPase $\mathrm{Na}^{+} / \mathrm{K}^{+}$transporting beta 1 polypeptide (Atplb1). Especially, Acly, Pck1, Ucpl, Atp1b1 also have an essential role in the ATP synthase process [43-46].

We performed mtDNA copy number measurements to quantitatively observe the mitochondrial changes in HDM-induced $\mathrm{AD}$-like group via $\mathrm{qRT}$-PCR. As the number of mitochondria increases, mitochondrial functional outputs such as oxygen consumption and ATP production increase. Therefore, it is necessary to determine the function of individual mitochondria by dividing functional output by number of mitochondria. Our results demonstrated that mitochondria copy number did not change in the $\mathrm{AD}$-like group compared to that of the control group. The changes in mitochondrial functional genes are only expected and a numerical increase does not occur.

We performed protein interaction network analysis to iden- 
Table 5. Differentially expressed genes in pathways associated with mitochondrial function by Kyoto Encyclopedia of Genes and Genomes (KEGG) and Gene Ontology (GO) analysis

\begin{tabular}{|c|c|c|c|c|c|c|}
\hline $\begin{array}{l}\text { Pathway } \\
\text { name }\end{array}$ & Gene name & Map ID & $\begin{array}{l}\text { Gene } \\
\text { symbol }\end{array}$ & $\begin{array}{l}\text { Gene } \\
\text { ID }\end{array}$ & $\begin{array}{l}\text { Fold- } \\
\text { change }\end{array}$ & p-value \\
\hline \multirow{11}{*}{$\begin{array}{r}\text { Metabolic } \\
\text { pathway }\end{array}$} & & KEGG:01100 & & & & $7.50528 \mathrm{E}-28$ \\
\hline & UDP-glucose ceramide glucosyltransferase & & Ugcg & 22234 & 3.4298 & $2.20686 \mathrm{E}-05$ \\
\hline & $\begin{array}{l}\text { Phosphoenolpyruvate carboxykinase } 1 \text {, } \\
\text { cytosolic }\end{array}$ & & Pck1 & 18534 & -2.8493 & 0.000149194 \\
\hline & ADP-ribosyltransferase $2 \mathrm{~b}$ & & Art2b & 11872 & 4.1334 & 0.000436275 \\
\hline & Mannosidase 1, alpha & & Man1a & 17155 & 2.6758 & 0.00092214 \\
\hline & Amine oxidase, copper containing 3 & & Aoc3 & 11754 & -2.6102 & 0.000982147 \\
\hline & $\begin{array}{l}\text { Phospholipase A2, group VII (platelet- } \\
\text { activating factor acetylhydrolase, plasma) }\end{array}$ & & Pla2g7 & 27226 & -2.6038 & 0.001028025 \\
\hline & Heparanase & & Hpse & 15442 & 2.7003 & 0.002399199 \\
\hline & Phospholipase C, gamma 2 & & Plcg2 & 234779 & 2.7840 & 0.002576994 \\
\hline & Inositol Polyphosphate-4-phosphatase, type II & & Inpp4b & 234515 & 2.6277 & 0.003007459 \\
\hline & Fatty acid synthase & & Fasn & 14104 & -2.2376 & 0.004242857 \\
\hline \multirow{11}{*}{$\begin{array}{l}\text { MAPK signaling } \\
\text { pathway }\end{array}$} & & KEGG:04010 & & & & $2.13015 \mathrm{E}-11$ \\
\hline & Protein kinase $\mathrm{C}$, beta & & Prkcb & 18751 & 4.7940 & 8.43315E-08 \\
\hline & RAS-related C3 botulinum substrate 2 & & Rac2 & 19354 & 2.5858 & 0.002214744 \\
\hline & $\begin{array}{l}\text { Calcium channel, voltage-dependent, gamma } \\
\text { subunit } 1\end{array}$ & & Cacng1 & 12299 & -2.2426 & 0.011240559 \\
\hline & RAS related protein $1 b$ & & Rap1b & 215449 & 2.1587 & 0.021951174 \\
\hline & TAO kinase 3 & & Taok3 & 330177 & 2.0617 & 0.091109254 \\
\hline & $\begin{array}{l}\text { Nuclear receptor subfamily } 4 \text {, group A, } \\
\text { member } 1\end{array}$ & & Nr4a1 & 15370 & -1.8287 & 0.122795267 \\
\hline & RAS-related protein-1a & & Rap1a & 109905 & 1.8729 & 0.13788196 \\
\hline & Colony stimulating factor 1 receptor & & Csf1r & 12978 & 1.8421 & 0.200175322 \\
\hline & Transforming growth factor, beta 1 & & Tgfb1 & 21803 & 1.8611 & 0.200327384 \\
\hline & Fibroblast growth factor 1 & & Fgf1 & 14164 & 1.8555 & 0.206473803 \\
\hline \multirow{11}{*}{$\begin{array}{l}\text { Cardiac muscle } \\
\text { contraction }\end{array}$} & & KEGG:04260 & & & & $5.07804 \mathrm{E}-10$ \\
\hline & Troponin C, cardiac/slow skeletal & & Tnnc1 & 21924 & 11.2839 & 0 \\
\hline & $\begin{array}{l}\text { Myosin, heavy polypeptide } 7 \text {, cardiac muscle, } \\
\text { beta }\end{array}$ & & Myh7 & 140781 & 25.3377 & 0 \\
\hline & $\begin{array}{l}\text { ATPase, } \mathrm{Ca}^{++} \text {transporting, cardiac muscle, } \\
\text { slow twitch } 2\end{array}$ & & Atp2a2 & 11938 & 8.3273 & 0 \\
\hline & Myosin, light polypeptide 3 & & Myl3 & 17897 & 5.7018 & $4.96498 \mathrm{E}-10$ \\
\hline & Tropomyosin 3, gamma & & Tpm3 & 59069 & 4.0864 & 8.07949E-08 \\
\hline & Actin, alpha, cardiac muscle 1 & & Actc1 & 11464 & -2.7027 & 7.15757E-06 \\
\hline & $\begin{array}{l}\text { ATPase, } \mathrm{Na}^{+} / \mathrm{K}^{+} \text {transporting, beta } 1 \\
\text { polypeptide }\end{array}$ & & Atp1b1 & 11931 & 3.0179 & $1.01881 \mathrm{E}-05$ \\
\hline & $\begin{array}{l}\text { Calcium channel, voltage-dependent, gamma } \\
\text { subunit } 1\end{array}$ & & Cacng1 & 12299 & -2.2426 & 0.011240559 \\
\hline & Tropomyosin 2, beta & & Tpm2 & 22004 & 1.8086 & 0.067947903 \\
\hline & $\begin{array}{l}\text { ATPase, } \mathrm{Na}^{+} / \mathrm{K}^{+} \text {transporting, beta } 2 \\
\text { polypeptide }\end{array}$ & & Atp1b2 & 11932 & -1.7850 & 0.123829945 \\
\hline \multirow{8}{*}{$\begin{array}{l}\text { cAMP signaling } \\
\text { pathway }\end{array}$} & & KEGG:04024 & & & & $3.53222 \mathrm{E}-09$ \\
\hline & $\begin{array}{l}\text { ATPase, } \mathrm{Ca}^{++} \text {transporting, cardiac muscle, } \\
\text { slow twitch } 2\end{array}$ & & Atp2a2 & 11938 & 8.3273 & 0 \\
\hline & $\begin{array}{l}\text { ATPase, } \mathrm{Na}^{+} / \mathrm{K}^{+} \text {transporting, beta } 1 \\
\text { polypeptide }\end{array}$ & & Atp1b1 & 11931 & 3.0179 & $1.01881 \mathrm{E}-05$ \\
\hline & RAS-related C3 botulinum substrate 2 & & Rac2 & 19354 & 2.5858 & 0.002214744 \\
\hline & Vav 1 oncogene & & Vav1 & 22324 & 2.8148 & 0.002719009 \\
\hline & $\begin{array}{l}\text { Rho-associated coiled-coil containing protein } \\
\text { kinase } 1\end{array}$ & & Rock1 & 19877 & 2.3129 & 0.0088963 \\
\hline & Coagulation factor II (thrombin) receptor & & $F 2 r$ & 14062 & 2.2565 & 0.020547361 \\
\hline & RAS related protein $1 \mathrm{~b}$ & & Rap1b & 215449 & 2.1587 & 0.021951174 \\
\hline
\end{tabular}


Table 5. Continued

\begin{tabular}{|c|c|c|c|c|c|c|}
\hline $\begin{array}{l}\text { Pathway } \\
\text { name }\end{array}$ & Gene name & Map ID & $\begin{array}{c}\text { Gene } \\
\text { symbol }\end{array}$ & $\begin{array}{l}\text { Gene } \\
\text { ID }\end{array}$ & $\begin{array}{l}\text { Fold- } \\
\text { change }\end{array}$ & p-value \\
\hline & Thyroid stimulating hormone receptor & & Tshr & 22095 & -2.2073 & 0.038586986 \\
\hline & ATPase, $\mathrm{Na}^{+} / \mathrm{K}^{+}$transporting, beta 2 polypeptide & & Atp1b2 & 11932 & -1.7850 & 0.123829945 \\
\hline & RAS-related protein-1a & & Rap1a & 109905 & 1.8729 & 0.13788196 \\
\hline \multirow{11}{*}{$\begin{array}{l}\text { Calcium signaling } \\
\text { pathway }\end{array}$} & & KEGG:04020 & & & & 0.00059103 \\
\hline & Troponin C, cardiac/slow skeletal & & Tnnc1 & 21924 & 11.2839 & 0 \\
\hline & $\begin{array}{l}\text { ATPase, } \mathrm{Ca}^{++} \text {transporting, cardiac muscle, } \\
\text { slow twitch } 2\end{array}$ & & Atp2a2 & 11938 & 8.3273 & 0 \\
\hline & Protein kinase $\mathrm{C}$, beta & & Prkcb & 18751 & 4.7940 & $8.43315 \mathrm{E}-08$ \\
\hline & PTK2 protein tyrosine kinase 2 beta & & $P t k 2 b$ & 19229 & 2.7416 & 0.002350974 \\
\hline & Phospholipase C, gamma 2 & & Plcg2 & 234779 & 2.7840 & 0.002576994 \\
\hline & Coagulation factor II (thrombin) receptor & & $F 2 r$ & 14062 & 2.2565 & 0.020547361 \\
\hline & Adrenergic receptor, beta 3 & & Adrb3 & 11556 & -2.0731 & 0.136087707 \\
\hline & Phospholipase C, delta 4 & & $\mathrm{Plcd} 4$ & 18802 & -1.8712 & 0.149640841 \\
\hline & Phosphorylase kinase gamma 1 & & Phkg1 & 18682 & -1.5328 & 0.544630124 \\
\hline & Cysteinyl leukotriene receptor 1 & & Cysltr1 & 58861 & 1.6576 & 0.904170421 \\
\hline \multirow{7}{*}{$\begin{array}{l}\text { Citrate cycle } \\
\text { (TCA cycle) }\end{array}$} & & KEGG:00020 & & & & 0.000801145 \\
\hline & Phosphoenolpyruvate carboxykinase 1, cytosolic & & Pck1 & 18534 & -2.8493 & 0.000149194 \\
\hline & ATP citrate lyase & & Acly & 104112 & -2.0581 & 0.047110874 \\
\hline & Pyruvate carboxylase & & $P C X$ & 18563 & -1.7369 & 0.294660312 \\
\hline & $\begin{array}{l}\text { Isocitrate dehydrogenase } 2\left(\mathrm{NADP}^{+}\right) \text {, } \\
\text { mitochondrial }\end{array}$ & & Idh2 & 269951 & 1.6504 & 0.41356214 \\
\hline & Dihydrolipoamide dehydrogenase & & Dld & 13382 & 1.5054 & 0.528579466 \\
\hline & Pyruvate dehydrogenase (lipoamide) beta & & $P d h b$ & 68263 & 1.5258 & 0.581213336 \\
\hline \multirow[t]{13}{*}{ Metabolic process } & & GO:0008152 & & & & $8.20872 \mathrm{E}-15$ \\
\hline & $\begin{array}{l}\text { Myosin, heavy polypeptide } 7 \text {, cardiac muscle, } \\
\text { beta }\end{array}$ & & Myh7 & 140781 & 9.2396 & 0 \\
\hline & Troponin C, cardiac/slow skeletal & & Tnnc1 & 21924 & 4.9515 & $1.56067 \mathrm{E}-10$ \\
\hline & Protein tyrosine phosphatase, receptor type, C & & Ptprc & 19264 & 1.6772 & $1.58413 \mathrm{E}-09$ \\
\hline & Cysteine and glycine-rich protein 3 & & Csrp3 & 13009 & 4.8441 & $6.54947 \mathrm{E}-09$ \\
\hline & Complement receptor 2 & & $\mathrm{Cr} 2$ & 12902 & 1.5179 & $1.3569 \mathrm{E}-07$ \\
\hline & Sarcolipin & & $S / n$ & 66402 & 4.7706 & $7.86542 \mathrm{E}-05$ \\
\hline & Ankyrin repeat domain 23 & & Ankrd2 & 56642 & 4.6069 & 0.000111618 \\
\hline & $\begin{array}{l}\text { TATA box binding protein (Tbp)-associated } \\
\text { factor, RNA polymerase I, D }\end{array}$ & & Taf1d & 75316 & 3.5900 & 0.000287478 \\
\hline & Fatty acid synthase & & Fasn & 14104 & -3.1209 & 0.00094772 \\
\hline & Egl-9 family hypoxia-inducible factor 3 & & Egln3 & 112407 & 3.0094 & 0.001295714 \\
\hline & Trans-2,3-enoyl-CoA reductase-like & & Tecrl & 243078 & 4.3562 & 0.001949038 \\
\hline & ATP citrate lyase & & Acly & 104112 & -2.7872 & 0.006506317 \\
\hline \multirow{11}{*}{$\begin{array}{l}\text { Oxidation-reduction } \\
\text { process }\end{array}$} & & GO:0055114 & & & & $1.13754 \mathrm{E}-08$ \\
\hline & Fatty acid synthase & & Fasn & 14104 & -3.1209 & 0.00094772 \\
\hline & Egl-9 family hypoxia-inducible factor 3 & & Egln3 & 112407 & 3.0094 & 0.001295714 \\
\hline & Trans-2,3-enoyl-coa reductase-like & & Tecrl & 243078 & 4.3562 & 0.001949038 \\
\hline & Stearoyl-Coenzyme A desaturase 1 & & Scd1 & 20249 & -2.3497 & 0.082571436 \\
\hline & Stearoyl-Coenzyme A desaturase 2 & & Scd2 & 20250 & -2.0047 & 0.35203592 \\
\hline & Aldehyde dehydrogenase 1 family, member L1 & & Aldh1/1 & 107747 & -1.6721 & 1 \\
\hline & Liver glycogen phosphorylase & & Pygl & 110095 & -1.6774 & 1 \\
\hline & Phosphogluconate dehydrogenase & & Pgd & 110208 & -1.6719 & 1 \\
\hline & $\begin{array}{l}\text { Adiponectin, } \mathrm{C} 1 \mathrm{Q} \text { and collagen domain } \\
\text { containing }\end{array}$ & & Adipoq & 11450 & -2.4945 & 1 \\
\hline & Amine oxidase, copper containing 3 & & Aoc3 & 11754 & -2.9607 & 1 \\
\hline
\end{tabular}


Table 5. Continued

\begin{tabular}{|c|c|c|c|c|c|c|}
\hline $\begin{array}{l}\text { Pathway } \\
\text { name }\end{array}$ & Gene name & Map ID & $\begin{array}{l}\text { Gene } \\
\text { symbol }\end{array}$ & $\begin{array}{l}\text { Gene } \\
\text { ID }\end{array}$ & $\begin{array}{l}\text { Fold- } \\
\text { change }\end{array}$ & p-value \\
\hline \multirow{9}{*}{$\begin{array}{l}\text { Calcium-mediated } \\
\text { signaling }\end{array}$} & & GO:0019722 & & & & 1.81205E-05 \\
\hline & $\begin{array}{l}\text { ATPase, } \mathrm{Ca}^{++} \text {transporting, cardiac muscle, slow } \\
\text { twitch } 2\end{array}$ & & Atp2a2 & 11938 & 3.7937 & $3.52028 \mathrm{E}-09$ \\
\hline & Calsequestrin 2 & & Casq2 & 12373 & 2.5131 & 0.082571436 \\
\hline & ATPase, $\mathrm{Na}^{+} / \mathrm{K}^{+}$transporting, beta 1 polypeptide & & Atp1b1 & 11931 & 1.9500 & 0.773408074 \\
\hline & Neural cell adhesion molecule 1 & & Ncam1 & 17967 & 1.5694 & 1 \\
\hline & Homer homolog 2 (Drosophila) & & Homer2 & 26557 & 1.5143 & 1 \\
\hline & LIM and cysteine-rich domains 1 & & Lmcd1 & 30937 & 1.7912 & 1 \\
\hline & Regulator of calcineurin 1 & & Rcan1 & 54720 & 1.6215 & 1 \\
\hline & Transmembrane protein 100 & & Tmem100 & 67888 & 1.6551 & 1 \\
\hline \multirow[t]{11}{*}{ Mitochondrion } & & GO:0005739 & & & & 0.000173505 \\
\hline & Troponin C, cardiac/slow skeletal & & Tnnc1 & 21924 & 4.9515 & $1.56067 \mathrm{E}-10$ \\
\hline & Fatty acid synthase & & Fasn & 14104 & -3.1209 & 0.00094772 \\
\hline & ATP citrate lyase & & Acly & 104112 & -2.7872 & 0.006506317 \\
\hline & DNA-damage-inducible transcript 4 & & Ddit4 & 74747 & -1.9880 & 0.923075132 \\
\hline & Acetyl-Coenzyme A carboxylase alpha & & Acaca & 107476 & -1.8971 & 1 \\
\hline & Aldehyde dehydrogenase 1 family, member L1 & & Aldh1/1 & 107747 & -1.6721 & 1 \\
\hline & $\begin{array}{l}\text { Cell death-inducing DNA fragmentation factor, } \\
\text { alpha subunit-like effector A }\end{array}$ & & Cidea & 12683 & -1.6864 & 1 \\
\hline & Cytochrome c oxidase subunit via polypeptide 1 & & Cox6a1 & 12861 & -1.6562 & 1 \\
\hline & Cytochrome c oxidase subunit viiia & & Cox8a & 12868 & -1.7344 & 1 \\
\hline & $\begin{array}{l}\text { Solute carrier family } 25 \text { (mitochondrial carrier, } \\
\text { citrate transporter), member } 1\end{array}$ & & Slc25a1 & 13358 & -2.0698 & 1 \\
\hline
\end{tabular}

tify the hub genes in 187 DEGs, which were screened in GO and KEGG analysis. The protein interaction network of the target gene can reveal the protein-protein interaction of HDM-induced AD-like in NC/Nga mice. Hub proteins identified were included in the chemokine family, muscle contraction process, inflammatory response, and immune response. Several hub proteins in the protein interaction networks might be associated with an $\mathrm{AD}$ like-related pathway, such as $C x c 113, C d 4, I 17$, and $C C r 7$ in cytokine interactions (Supplementary Fig. 1).

We identified the association between $\mathrm{AD}$ and mitochondrial functions at the gene level and determined the stimulated genes and pathways. In summary, our study deepens our understanding of the genome-wide transcriptional changes of HDM-induced AD-like symptoms in the skeletal muscle of NC/Nga mice, providing to the discovery of genes that could be used as AD clinical biomarkers.

\section{ACKNOWLEDGEMENTS}

This study was supported by Korea Institute of Planning and Evaluation for Technology in Food, Agriculture, Forestry and Fisheries (IPET) through the Agri-Bioindustry Technology Development Program, funded by Ministry of Agriculture, Food and Rural Affairs (MAFRA) (117046-3); the National Research Foundation of Korea (NRF) grant funded by the Korea govern- ment (No. NRF-2017R1A2B4002052, 2017R1D1A1B06035273); and the Chung-Ang University Graduate Research Scholarship in 2015.

\section{CONFLICTS OF INTEREST}

The authors declare no conflicts of interest.

\section{SUPPLEMENTARY MATERIALS}

Supplementary data including two tables and one figure can be found with this article online at http://pdf.medrang.co.kr/paper/ pdf/Kjpp/Kjpp2019-23-05-10-s001.pdf.

\section{REFERENCES}

1. Yosipovitch G, Greaves MW, Schmelz M. Itch. Lancet. 2003;361:690694.

2. Williams HC. Epidemiology of atopic dermatitis. Clin Exp Dermatol. 2000;25:522-529.

3. Weidinger S, Novak N. Atopic dermatitis. Lancet. 2016;387:11091122 .

4. Ikoma A, Steinhoff M, Ständer S, Yosipovitch G, Schmelz M. The neurobiology of itch. Nat Rev Neurosci. 2006;7:535-547. 
5. Goebels N, Michaelis D, Wekerle H, Hohlfeld R. Human myoblasts as antigen-presenting cells. J Immunol. 1992;149:661-667.

6. Curnow J, Corlett L, Willcox N, Vincent A. Presentation by myoblasts of an epitope from endogenous acetylcholine receptor indicates a potential role in the spreading of the immune response. $J$ Neuroimmunol. 2001;115:127-134.

7. Gallucci S, Provenzano C, Mazzarelli P, Scuderi F, Bartoccioni E. Myoblasts produce IL-6 in response to inflammatory stimuli. Int Immunol. 1998;10:267-273.

8. Nagaraju K. Immunological capabilities of skeletal muscle cells. Acta Physiol Scand. 2001;171:215-223.

9. Wiendl H, Mitsdoerffer M, Schneider D, Chen L, Lochmüller H, Melms A, Weller M. Human muscle cells express a B7-related molecule, B7-H1, with strong negative immune regulatory potential: a novel mechanism of counterbalancing the immune attack in idiopathic inflammatory myopathies. FASEB J. 2003;17:1892-1894.

10. Koziol-White CJ, Panettieri RA Jr. Airway smooth muscle and immunomodulation in acute exacerbations of airway disease. Immunol Rev. 2011;242:178-185.

11. Damera G, Tliba O, Panettieri RA Jr. Airway smooth muscle as an immunomodulatory cell. Pulm Pharmacol Ther. 2009;22:353-359.

12. Aguilera-Aguirre L, Bacsi A, Saavedra-Molina A, Kurosky A, Sur S, Boldogh I. Mitochondrial dysfunction increases allergic airway inflammation. J Immunol. 2009;183:5379-5387.

13. West AP, Shadel GS, Ghosh S. Mitochondria in innate immune responses. Nat Rev Immunol. 2011;11:389-402.

14. Trian T, Benard G, Begueret H, Rossignol R, Girodet PO, Ghosh D, Ousova O, Vernejoux JM, Marthan R, Tunon-de-Lara JM, Berger P. Bronchial smooth muscle remodeling involves calcium-dependent enhanced mitochondrial biogenesis in asthma. J Exp Med. 2007;204:3173-3181.

15. Girodet PO, Allard B, Thumerel M, Begueret H, Dupin I, Ousova O, Lassalle R, Maurat E, Ozier A, Trian T, Marthan R, Berger P. Bronchial smooth muscle remodeling in nonsevere asthma. Am J Respir Crit Care Med. 2016;193:627-633.

16. Xu YD, Cui JM, Wang Y, Yin LM, Gao CK, Liu YY, Yang YQ. The early asthmatic response is associated with glycolysis, calcium binding and mitochondria activity as revealed by proteomic analysis in rats. Respir Res. 2010;11:107.

17. Bunyavanich S, Schadt EE, Himes BE, Lasky-Su J, Qiu W, Lazarus R, Ziniti JP, Cohain A, Linderman M, Torgerson DG, Eng CS, PinoYanes M, Padhukasahasram B, Yang JJ, Mathias RA, Beaty TH, Li X, Graves P, Romieu I, Navarro Bdel R, et al. Integrated genome-wide association, coexpression network, and expression single nucleotide polymorphism analysis identifies novel pathway in allergic rhinitis. BMC Med Genomics. 2014;7:48.

18. Kay AB. Allergy and allergic diseases. First of two parts. N Engl J Med. 2001;344:30-37.

19. Raby BA, Klanderman B, Murphy A, Mazza S, Camargo CA Jr, Silverman EK, Weiss ST. A common mitochondrial haplogroup is associated with elevated total serum IgE levels. J Allergy Clin Immunol. 2007;120:351-358.

20. Bradley M, Kockum I, Söderhäll C, Van Hage-Hamsten M, Luthman H, Nordenskjöld M, Wahlgren CF. Characterization by phenotype of families with atopic dermatitis. Acta Derm Venereol. 2000;80:106-110.

21. Dold S, Wjst M, von Mutius E, Reitmeir P, Stiepel E. Genetic risk for asthma, allergic rhinitis, and atopic dermatitis. Arch Dis Child. 1992;67:1018-1022.

22. Morar N, Willis-Owen SA, Moffatt MF, Cookson WO. The genetics of atopic dermatitis. J Allergy Clin Immunol. 2006;118:24-34.

23. Iyer D, Mishra N, Agrawal A. Mitochondrial function in allergic disease. Curr Allergy Asthma Rep. 2017;17:29.

24. Spergel JM, Paller AS. Atopic dermatitis and the atopic march. J Allergy Clin Immunol. 2003;112(6 Suppl):S118-S127.

25. Čepelak I, Dodig S, Pavić I. Filaggrin and atopic march. Biochem Med (Zagreb). 2019;29:020501.

26. Guo W, Jiang L, Bhasin S, Khan SM, Swerdlow RH. DNA extraction procedures meaningfully influence qPCR-based mtDNA copy number determination. Mitochondrion. 2009;9:261-265.

27. Szklarczyk D, Franceschini A, Wyder S, Forslund K, Heller D, Huerta-Cepas J, Simonovic M, Roth A, Santos A, Tsafou KP, Kuhn M, Bork P, Jensen LJ, von Mering C. STRING v10: protein-protein interaction networks, integrated over the tree of life. Nucleic Acids Res. 2015;43:D447-D452.

28. Garcia G, Godot V, Humbert M. New chemokine targets for asthma therapy. Curr Allergy Asthma Rep. 2005;5:155-160.

29. Cannistraci CV, Ogorevc J, Zorc M, Ravasi T, Dovc P, Kunej T. Pivotal role of the muscle-contraction pathway in cryptorchidism and evidence for genomic connections with cardiomyopathy pathways in RASopathies. BMC Med Genomics. 2013;6:5.

30. Li H, Chiappinelli KB, Guzzetta AA, Easwaran H, Yen RW, Vatapalli R, Topper MJ, Luo J, Connolly RM, Azad NS, Stearns V, Pardoll DM, Davidson N, Jones PA, Slamon DJ, Baylin SB, Zahnow CA, Ahuja N. Immune regulation by low doses of the DNA methyltransferase inhibitor 5-azacitidine in common human epithelial cancers. Oncotarget. 2014;5:587-598.

31. Forner F, Kumar C, Luber CA, Fromme T, Klingenspor M, Mann M. Proteome differences between brown and white fat mitochondria reveal specialized metabolic functions. Cell Metab. 2009;10:324-335.

32. Falk MJ, Zhang Z, Rosenjack JR, Nissim I, Daikhin E, Nissim I, Sedensky MM, Yudkoff M, Morgan PG. Metabolic pathway profiling of mitochondrial respiratory chain mutants in C. elegans. Mol Genet Metab. 2008;93:388-397.

33. Jaakkola MS, Ieromnimon A, Jaakkola JJ. Are atopy and specific IgE to mites and molds important for adult asthma? J Allergy Clin Immunol. 2006;117:642-648.

34. Sebastiani S, Albanesi C, De PO, Puddu P, Cavani A, Girolomoni G. The role of chemokines in allergic contact dermatitis. Arch Dermatol Res. 2002;293:552-559.

35. Bao L, Shi VY, Chan LS. IL-4 regulates chemokine CCL26 in keratinocytes through the Jak1, 2/Stat6 signal transduction pathway: Implication for atopic dermatitis. Mol Immunol. 2012;50:91-97.

36. Danielewicz H. Hits and defeats of genome-wide association studies of atopy and asthma. J Appl Biomed. 2017;15:161-168.

37. Grammatikos AP. The genetic and environmental basis of atopic diseases. Ann Med. 2008;40:482-495.

38. Robbins SH, Walzer T, Dembélé D, Thibault C, Defays A, Bessou G, Xu H, Vivier E, Sellars M, Pierre P, Sharp FR, Chan S, Kastner $\mathrm{P}$, Dalod M. Novel insights into the relationships between dendritic cell subsets in human and mouse revealed by genome-wide expression profiling. Genome Biol. 2008;9:R17.

39. Li H, Toh PZ, Tan JY, Zin MT, Lee CY, Li B, Leolukman M, Bao H, Kang L. Selected biomarkers revealed potential skin toxicity caused 
by certain copper compounds. Sci Rep. 2016;6:37664.

40. Cakebread JA, Haitchi HM, Holloway JW, Powell RM, Keith T, Davies DE, Holgate ST. The role of ADAM33 in the pathogenesis of asthma. Springer Semin Immunopathol. 2004;25:361-375.

41. Pinto LA, Steudemann L, Depner M, Klopp N, Illig T, Weiland SK, von Mutius E, Kabesch M. STAT1 gene variations, IgE regulation and atopy. Allergy. 2007;62:1456-1461.

42. Johansen C, Rittig AH, Mose M, Bertelsen T, Weimar I, Nielsen J, Andersen T, Rasmussen TK, Deleuran B, Iversen L. STAT2 is involved in the pathogenesis of psoriasis by promoting CXCL11 and CCL5 production by keratinocytes. PLoS One. 2017;12:e0176994.

43. Zaidi N, Swinnen JV, Smans K. ATP-citrate lyase: a key player in cancer metabolism. Cancer Res. 2012;72:3709-3714.
44. Infantino V, Iacobazzi V, Palmieri F, Menga A. ATP-citrate lyase is essential for macrophage inflammatory response. Biochem Biophys Res Commun. 2013;440:105-111.

45. Millward CA, Desantis D, Hsieh CW, Heaney JD, Pisano S, Olswang Y, Reshef L, Beidelschies M, Puchowicz M, Croniger CM. Phosphoenolpyruvate carboxykinase (Pck1) helps regulate the triglyceride/ fatty acid cycle and development of insulin resistance in mice. $J$ Lipid Res. 2010;51:1452-1463.

46. Porter C, Herndon DN, Chondronikola M, Chao T, Annamalai P, Bhattarai N, Saraf MK, Capek KD, Reidy PT, Daquinag AC, Kolonin MG, Rasmussen BB, Borsheim E, Toliver-Kinsky T, Sidossis LS. Human and mouse brown adipose tissue mitochondria have comparable UCP1 function. Cell Metab. 2016;24:246-255. 